\title{
BINDING INTERACTION BETWEEN (-)-EPIGALLOCATECHIN-3- GALLATE (EGCG) OF GREEN TEA AND PEPSIN
}

\author{
Y. Li, F.Q. Lu, Y. Feng, Z.D. He and X.L. Wu* \\ School of Medicine, Shenzhen University, Shenzhen, Guangdong Province. PR China
}

(Received: 4 March 2015; accepted: 21 April 2015)

\begin{abstract}
Analysis of the binding interaction of (-)-epigallocatechin-3-gallate (EGCG) and pepsin is important for understanding the inhibition of digestive enzymes by tea polyphenols. We studied the binding of EGCG to pepsin using fluorescence spectroscopy, Fourier transform infrared spectroscopy, isothermal titration calorimetry, and protein-ligand docking. We found that EGCG could inhibit pepsin activity. According to thermodynamic parameters, a negative $\Delta G$ indicated that the interaction between EGCG and pepsin was spontaneous, and the electrostatic force accompanied by hydrophobic binding forces may play major role in the binding. Data from multi-spectroscopy and docking studies suggest that EGCG could bind pepsin with a change in the native conformation of pepsin. Our results provide further understanding of the nature of the binding interactions between catechins and digestive enzymes.
\end{abstract}

Keywords: EGCG, green tea, pepsin, digestion, interaction

Green tea has many potential health benefits attributed to tea polyphenols, in particular catechins, which have strong antioxidative activity (SABU et al., 2010). Major tea catechins include (-)-epigallocatechin-3-gallate (EGCG), (-)-epigallocatechin, (-)-epicatechingallate and (-)-epicatechin. EGCG is the most potent constituent of green tea and represents $50 \%$ of the total catechins (Kilmartin \& Hsu, 2003). Tea polyphenols are soluble in water and can be added to various foods as natural antioxidants.

However, tea polyphenols may reduce food digestibility by inhibiting digestive enzymes. Studies have shown that phenolic compounds from plants have a strong ability to interact with food proteins and show strong complexing abilities with enzymes (SPEnCER et al., 1988; Dubeau et al., 2010; Yuksel et al., 2010; BAndyopadhyay et al., 2012). The binding interactions of tea catechins with digestive enzymes were found to denature the catalytic activity of enzymes, which reduced food digestibility (HE et al., 2006). Pepsin is a proteinase present in animals and has a significant role in the digestive process. Therefore, studying the interactions of EGCG and pepsin are important to understand its mechanism of action to inhibit pepsin.

Pepsin contains 2 tryptophans (Trp) and 4 tyrosines (Tyr) therefore, fluorescence quenching can be used with the intrinsic tryptophan of Trp and Tyr to determine the binding affinities of EGCG and pepsin and characterise the nature of the EGCG-pepsin complex.

In this study, we detected the inhibitory effect of EGCG on pepsin activity by studying the interaction of EGCG and pepsin with fluorescence spectroscopy, Fourier transform infrared (FTIR) spectroscopy, and isothermal titration calorimetry (ITC). To substantiate our experimental studies, docking studies were performed. Important information, such as the change in protein secondary structure and association constant, are reported. We aimed to help understand the nature of binding between catechins and digestive enzymes.

\footnotetext{
* To whom correspondence should be addressed.

Phone: +8675586671909; fax: +86 75586671906; e-mail: wxl@szu.edu.cn
} 


\section{Materials and methods}

\subsection{Materials}

EGCG (with purity $>99 \%$ ) was from Chengdu Biopurify Photochemicals (China) and porcine pepsin (EC 3.4.23.1) was from Sigma Chemical Co. (USA). A working solution of pepsin was prepared with $0.02 \mathrm{M} \mathrm{HCl}(\mathrm{pH} 2.0)$.

The EGCG-pepsin complex for FTIR was prepared as described (PRIGENT et al., 2003). In brief, samples of $0.1 \%(\mathrm{w} / \mathrm{v})$ pepsin were incubated in $0.02 \mathrm{M} \mathrm{HCl}(\mathrm{pH} 2.0)$ for $1 \mathrm{~h}$ with EGCG at a ratio of $50 \mathrm{~mol}$ EGCG per mole of protein at room temperature. Blanks without EGCG were also incubated during the same period. All samples were dialyzed overnight after incubation in Slide-A-Lyzer minidialysis units (molecular weight cutoff $10 \mathrm{kDa}$ ) (Pierce Chemical, USA) against distilled water at $4{ }^{\circ} \mathrm{C}$ to remove the free EGCG.

\subsection{Assay of pepsin activity}

Pepsin activity was detected by the method as described with slight modification (ZHU et al., 2010). Pepsin $\left(6.0 \times 10^{-6} \mathrm{M}\right)$ in $0.02 \mathrm{M} \mathrm{HCl}(\mathrm{pH} 2.0)$ was mixed with different concentrations of EGCG $\left(0,6.0,12.0,18.0,24.0,36.0\right.$, and $\left.42.0 \times 10^{-6} \mathrm{M}\right)$ at $37{ }^{\circ} \mathrm{C}$ for $30 \mathrm{~min}$. Bovine haemoglobin solution $(4 \mathrm{ml})$ was used to dissolve the enzyme solutions. After $10 \mathrm{~min}$, the reaction was terminated by adding $8 \mathrm{ml}$ of $5 \%$ trichloroacetic acid. The mixture stood for 10 min and was then centrifuged at 12000 r.p.m. for 10 min twice. The activity of enzyme was measured at optical density of supernatant of $275 \mathrm{~nm}$. The initial activity of pepsin was 1200 $\mathrm{U} \mathrm{g}^{-1}$. Thus, the activity of the enzyme after EGCG treatment was calculated as follows:

$$
\text { Activity }\left(\mathrm{U} \mathrm{g}^{-1}\right)=1200 \times\left[\mathrm{OD}_{275}(\text { treated pepsin }) / \mathrm{OD}_{275}(\text { original pepsin })\right]
$$

The inhibition pattern of EGCG was determined by Lineweaver-Burk plot analysis calculated according to Michaelis-Menten kinetics. The pepsin activity was measured at different bovine haemoglobin concentrations $\left(5-20 \mathrm{mg} \mathrm{ml}^{-1}\right)$ as a substrate after treatment with EGCG $(0,250,500 \mu \mathrm{M})$. All samples were analysed in triplicate.

\subsection{Isothermal titration calorimetry (ITC) experiment}

ITC experiments involved use of a MicroCal Auto-ITC ${ }_{200}$ calorimeter (GE, Stockholm) at $37{ }^{\circ} \mathrm{C}$. Pepsin and EGCG were prepared in $30 \mathrm{mM} \mathrm{HCl}$ buffer. Titrant was set at $5.4 \mathrm{mM}$ pepsin solution and titrate was set at $54 \mathrm{mM} \mathrm{EGCG.} \mathrm{EGCG} \mathrm{at} 2 \mu \mathrm{l}$ was injected 14 times into pepsin at 120-s intervals and 1000 r.p.m. A control experiment involved setting EGCG suspension as titrate and $30 \mathrm{mM} \mathrm{HCl}$ buffer as titrant. The raw data were analysed by nonlinear regression with a single-site binding model by using ORIGIN v7.0 (MicroCal Inc.).

\subsection{Fluorescence spectroscopy}

Quantities of $1.0 \times 10^{-3} \mathrm{M}$ EGCG solution were prepared with $0.02 \mathrm{M} \mathrm{HCl}(\mathrm{pH} 2.0)$ and transferred to a $10-\mathrm{ml} \mathrm{flask,} \mathrm{treated} \mathrm{with} 1.0 \times 10^{-5} \mathrm{M}$ pepsin $(1.0 \mathrm{ml})$, and topped up with 0.02 $\mathrm{M} \mathrm{HCl}\left(\mathrm{pH} 2.0\right.$ ) to a final volume of $10 \mathrm{ml}$, then incubated at $27^{\circ} \mathrm{C}$ and $37^{\circ} \mathrm{C}$ for $1 \mathrm{~h}$ each. 
Fluorescence spectra were recorded by use of a Hitachi-850 spectrofluorometer (Hitachi Co., Japan) with excitation wavelength $280 \mathrm{~nm}$ and emission from 300 to $450 \mathrm{~nm}$. The excitation and emission bandwidths were $5 \mathrm{~nm}$. The operations were executed at a fixed temperature of $27^{\circ} \mathrm{C}$ and $37^{\circ} \mathrm{C}$.

\subsection{FTIR spectroscopy}

Samples were measured at room temperature by use of an FTIR-8300PCS spectrometer (Shimadzu Co., Japan). The spectra-processing procedure involved collecting $\mathrm{KBr}$ spectra. To obtain the FTIR spectra, the absorbance of $\mathrm{KBr}$ was subtracted from the spectra of the samples. All spectra were produced by the attenuated total reflection (ATR) method with a resolution $4 \mathrm{~cm}^{-1}$, with 36 scans.

\subsection{IR spectra processing}

The secondary structure information of samples was determined as described (BYLER \& SUSI, 1986). Secondary derivative calculations and Fourier self-deconvolution was used to calculate the number and position of the component bands. To quantify the area of each component, a multiple Gaussian curve-fitting process was conducted in the region 1700 to $1600 \mathrm{~cm}^{-1}$ of the amide I band based on the parameters above. The relative percentage of the secondary structural elements was calculated from the area under the Gaussian curve (SusI \& BYLeR, 1986; Dong et al., 1990).

\subsection{Molecular modelling and docking}

Docking studies involved use of MOE software. The pepsin structure was downloaded from the Brookhaven Protein Data Bank (PDB) (accession no.: 5PEP). Pepsin was considered rigid and EGCG fully flexible during docking. The docked complex was optimized on the basis of its fit within the receptor pocket that accounts for continuum and discrete electrostatics, Van der Waals interaction, hydrophobicity, hydrogen bonding and entropy.

\section{Results and discussion}

\subsection{Inhibitory effect of EGCG on pepsin activity}

Pepsin activity decreased marginally at a molar ratio of 1:1 to EGCG (Fig. 1A). The activity was reduced with increasing molar ratio of EGCG and decreased to $65.3 \%$ with $42.0 \times 10^{-6} \mathrm{M}$ EGCG in the treated sample. The activity of enzymes can affect the conformational mobility of the protein structure (SinKovits et al., 2007). Figure 1B reports the reaction kinetics of pepsin by varying the substrate concentration and EGCG concentration. EGCG inhibited the pepsin activity dose-dependently, decreasing $V_{\max }$, with no change in $K_{m}$. Thus, the inhibition was non-competitive. 
A

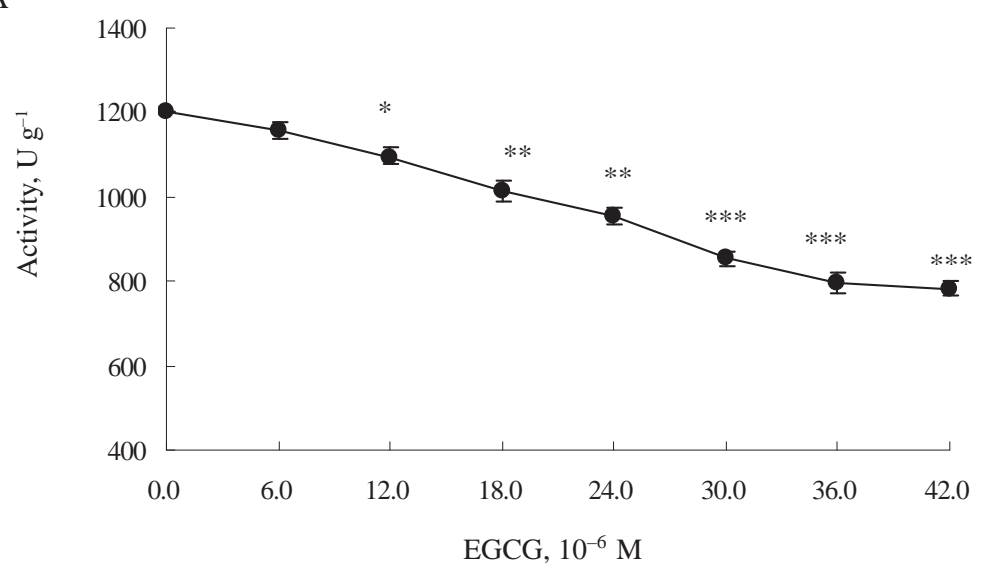

B

I

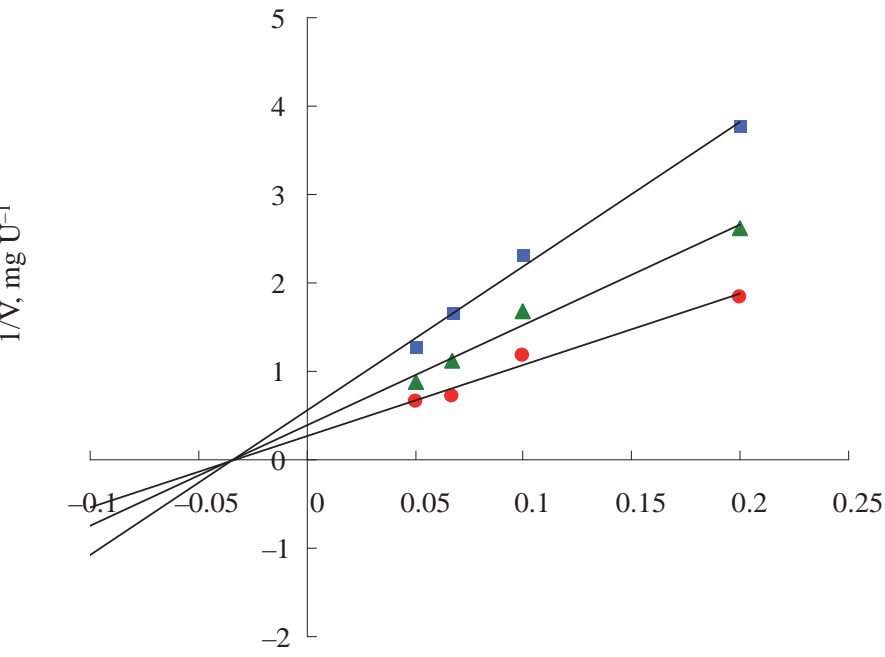

$1 /[\mathrm{S}], \mathrm{ml} \mathrm{mg}^{-1}$

Fig. 1. (A): Effect of (-)-epigallocatechin-3-gallate (EGCG) on pepsin activity. Data are mean $\pm \mathrm{D}\left(\mathrm{n}=3,{ }^{*} \mathrm{P}<0.05\right.$, $\left.{ }^{* *} \mathrm{P}<0.01,{ }^{* * *} \mathrm{P}<0.001\right)$. (B): Lineweaver-Burk plot of the reaction of pepsin in the presence of EGCG. ๑: Control; $\mathbf{A}: 250 \mu \mathrm{M}$; - $500 \mu \mathrm{M}$

\subsection{Fluorescence spectroscopy}

The tryptophan residues of pepsin fluorescence intensity decreased with increasing EGCG concentration, so EGCG could bind with pepsin (Fig. 2). 
A
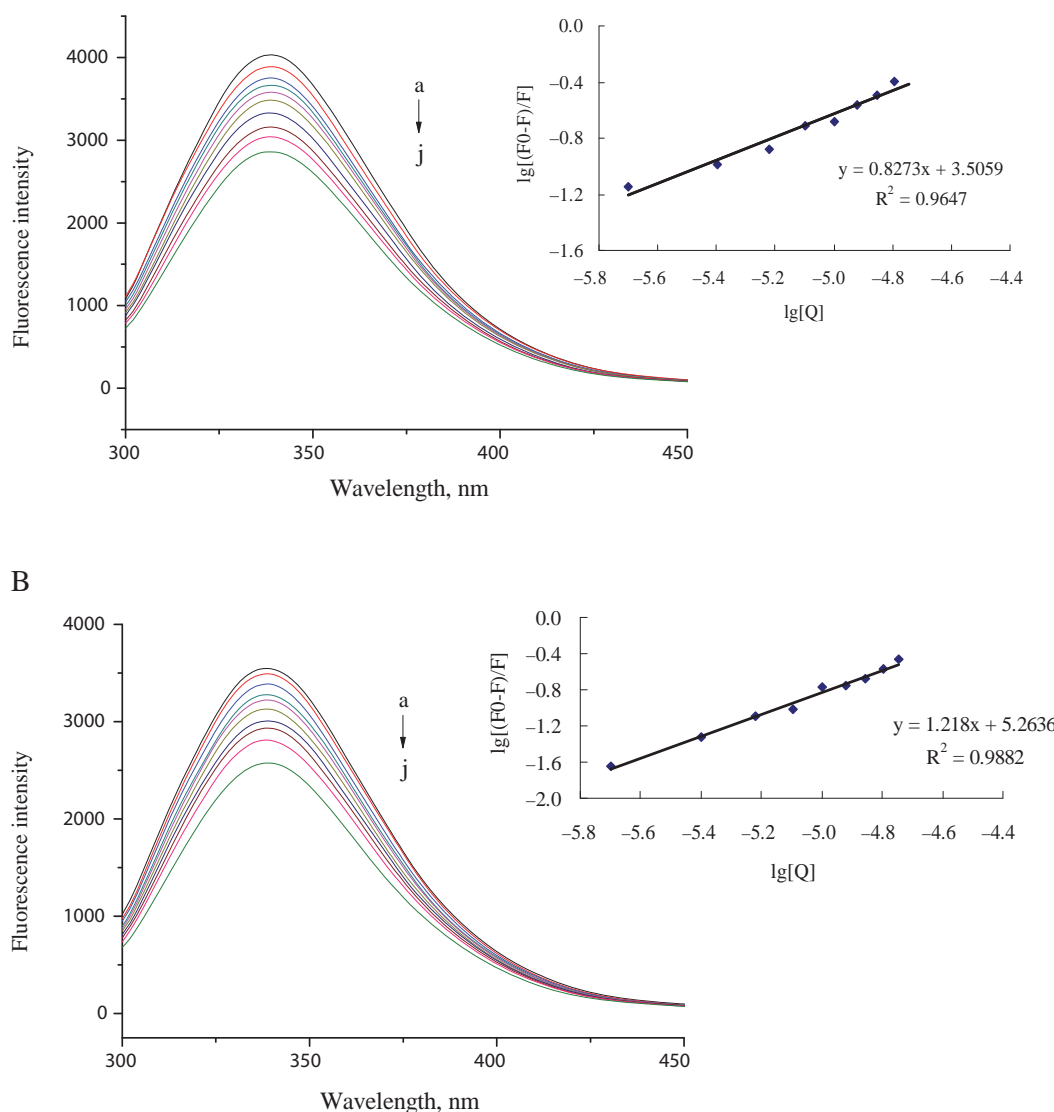

Fig. 2. The quenching effect of EGCG on pepsin fluorescence intensity, $\lambda_{\mathrm{ex}}=280 \mathrm{~nm}$. (a-j) Pepsin was $1.0 \times 10^{-6} \mathrm{M}$, and EGCG concentration increased from $0.0,2.0,4.0,6.0,8.0,10.0,12.0,14.0,16.0,18.0\left(\times 10^{-6} \mathrm{M}\right) .(\mathrm{A}): 27^{\circ} \mathrm{C}$; (B): $37^{\circ} \mathrm{C}$.

At the outset, we assumed that the interaction between pepsin and EGCG was dynamic. The mechanism of dynamic quenching can be characterised by the Stern-Volmer equation (LAKOWICZ, 1999):

$$
F 0 / F=1+K q \tau_{0}[Q]=1+K s v[Q]
$$

where $K_{q}, \tau_{0}, K_{S V}$ and $[Q]$ are the quenching rate constant of the bimolecule, the average lifetime of the molecule without quencher, the dynamic quenching constant, and the concentration of the quencher, respectively. $F$ and $F_{0}$ are the fluorescence intensities after and before the addition of quencher, respectively. We calculated the corresponding dynamic quenching constant $K_{S V}$ at $27^{\circ} \mathrm{C}$ and $37^{\circ} \mathrm{C}$ as $2.31 \times 10^{5} 1 \mathrm{~mol}^{-1}(\mathrm{r}=0.991)$ and $2.04 \times 10^{5} 1 \mathrm{~mol}^{-}$ ${ }^{1}(\mathrm{r}=0.986)$, respectively. With fluorescence life time of the biopolymer $10^{-8} \mathrm{~S}$ (LAKOwICZ \& Weber, 1973), the quenching constant $K_{q}$ at $27^{\circ} \mathrm{C}$ and $37^{\circ} \mathrm{C}$ was $2.31 \times 10^{13}$ and $2.04 \times 10^{13} 1$ $\mathrm{mol}^{-1} \mathrm{~s}^{-1}$, respectively. 
According to the literature (JIANG et al., 2002), $K_{S V}$ increasing with increasing temperature is dynamic quenching, and the maximum scatter collision quenching constant of various quenchers with the biopolymer is $2.0 \times 10^{10} 1 \mathrm{~mol}^{-1} \mathrm{~s}^{-1}$. Considering that the $K_{S V}$ of EGCGinitiated pepsin quenching decreased with increasing temperature and $K_{q}$ was much greater than $2.0 \times 10^{10} 1 \mathrm{~mol}^{-1} \mathrm{~s}^{-1}$, the nature of pepsin quenching procedure was not dynamic but rather static, owing to the formation of the EGCG-pepsin complex.

The relationship between fluorescence quenching intensity and the concentration of quenchers for static quenching can be described as follows (WANG et al., 2006):

$$
\lg \left(F_{0}-F\right) / F=\lg K_{a}+\operatorname{ng}[Q]
$$

where $\mathrm{n}$ and $K_{a}$ are the number of binding sites per enzyme and the binding constant, respectively. The double-logarithm algorithm was assessed by Eq. 2. According to the double-logarithm algorithm, the binding constant $\left(K_{a}\right)$ at $27{ }^{\circ} \mathrm{C}$ and $37{ }^{\circ} \mathrm{C}$ was $3.20 \times 10^{3}$ $1 \mathrm{~mol}^{-1}(\mathrm{r}=0.982)$ and $1.83 \times 10^{5} 1 \mathrm{~mol}^{-1}(\mathrm{r}=0.994)$, respectively. The number of binding sites per pepsin (n) was 0.83 and 1.22 , respectively. Therefore, the number of binding sites per pepsin depended on temperature $\left(27^{\circ} \mathrm{C}\right.$ to $\left.37^{\circ} \mathrm{C}\right)$. Non-ionic interactions are involved in the binding of EGCG with pepsin as a result of the increase in the binding constant with increasing temperature. Temperature might have affected the stability of the EGCG-pepsin system and the diffusion coefficient. The increased temperature might lead to lower stability of the EGCG-pepsin system and increase the diffusion coefficient because of competition between stability of the EGCG-pepsin system and the diffusion coefficient.

According to the van't Hoff equation, free energy change $(\Delta G)$ can be calculated as $\Delta G=-\mathrm{RT} \ln \mathrm{K}$, where $\mathrm{K}$ is the binding constant at the corresponding $\mathrm{T}, \mathrm{T}$ and $\mathrm{R}$ are the experimental temperature and the gas constant, respectively. The $\Delta G$ was calculated as $-31.29 \mathrm{~kJ} \mathrm{~mol}^{-1}$ at $37^{\circ} \mathrm{C}$.

\subsection{ITC}

We obtained detailed thermodynamic and binding constant data $-\Delta S, \Delta H, \Delta \mathrm{G}, K_{a}$, and number of binding sites per protein (n) - by ITC intermolecular force analysis of pepsin and EGCG. Figure 3 shows typical exothermic heat pulse. The $n$ and $\mathrm{K}_{\mathrm{a}}$ of 1.14 and $9.15 \times 10^{3}$ $1 \mathrm{~mol}^{-1}$, respectively, were similar to findings from fluorescence spectroscopy.

$\Delta S, \Delta H$, and $\Delta G$ were $22.7,-2.18$, and $-8.94 \mathrm{~kJ} \mathrm{~mol}^{-1}$, respectively. $\Delta G$ is negative, so the interaction between EGCG and pepsin was spontaneous. Meanwhile, if $\Delta H$ is much less than $60 \mathrm{~kJ} \mathrm{~mol}^{-1}$, the interaction is non-covalent (XIE et al., 2005). The positive $\Delta S$ and negative $\Delta H$ indicate that the interaction is mostly an electrostatic force, accompanied by hydrophobic binding (Ross \& Subramanian, 1981). Non-covalent binding, including hydrophobic binding with an $\mathrm{H}$ bond and electrostatic force, is often non-specific and weak but may alter the conformation and function of the enzyme (Wu et al., 2013).

Therefore, we analysed the change in protein structure by synchronous fluorescence and FTIR. 


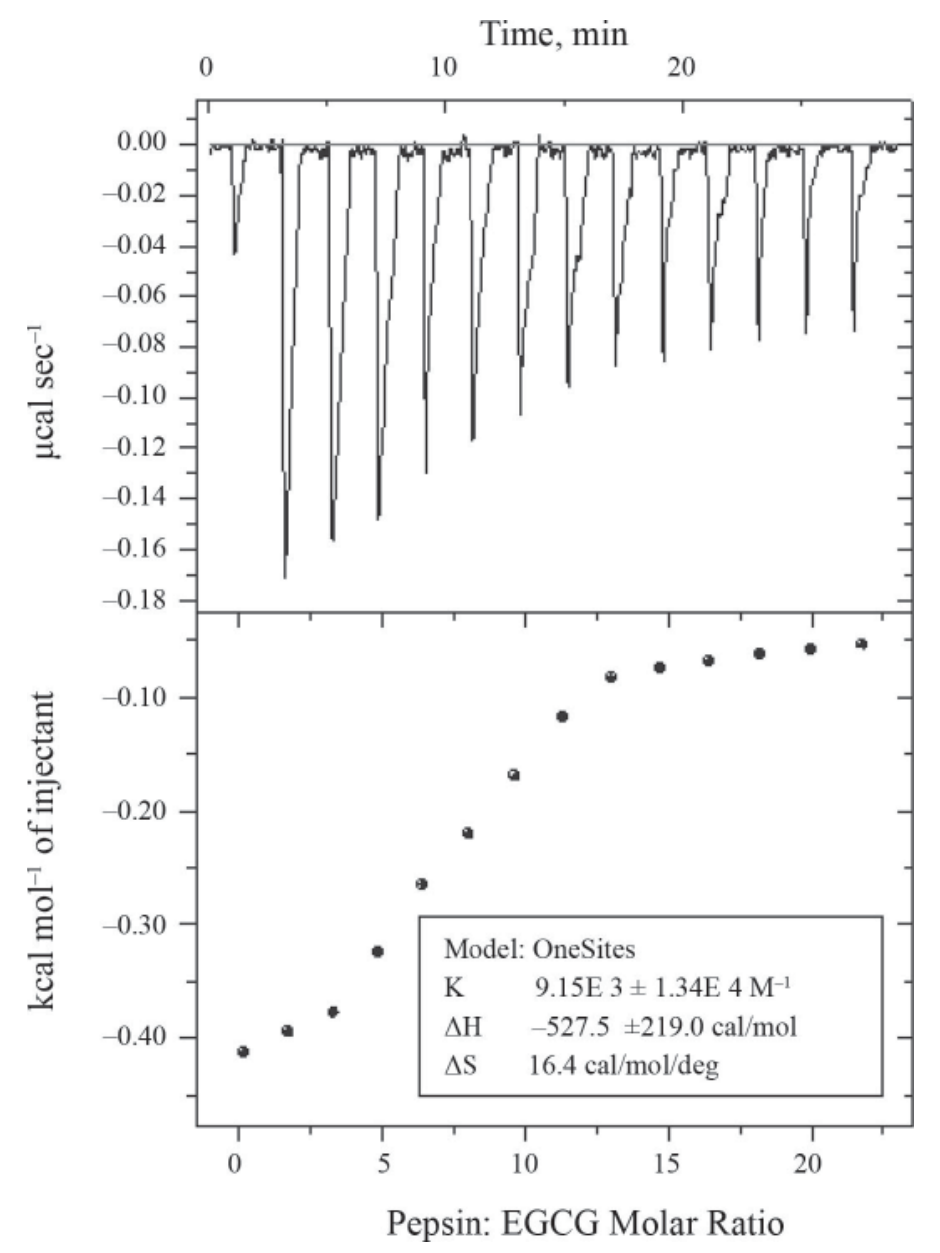

Fig. 3. Results of isothermal titration calorimetry (ITC) for EGCG binding to pepsin in $30 \mathrm{mM} \mathrm{HCl}$ buffer at $37^{\circ} \mathrm{C}$.

\subsection{Pepsin conformation after EGCG binding}

The synchronous fluorescence spectra for the interaction between EGCG and pepsin in Figure $4 \mathrm{~A}$ reveal that with the addition of EGCG, the fluorescence intensity of pepsin decreased regularly and produced a red shift $(10 \mathrm{~nm})$ of $\lambda_{\max }$, so EGCG was located close to the Tyr residues (Tyr20, Tyr42, Tyr99, and Tyr102) of pepsin. Pepsin also showed regular quenching with a red shift $(11 \mathrm{~nm})$ of the $\lambda_{\text {max }}$ (Fig. 4B), so EGCG was close to the Trp residues (Trp19 and Trp61) of pepsin. The decrease in fluorescence intensity may be due to the shielding effect of EGCG binding to pepsin (Lakowicz \& Weber, 1973), with a conformational change of pepsin as a result of EGCG binding. 

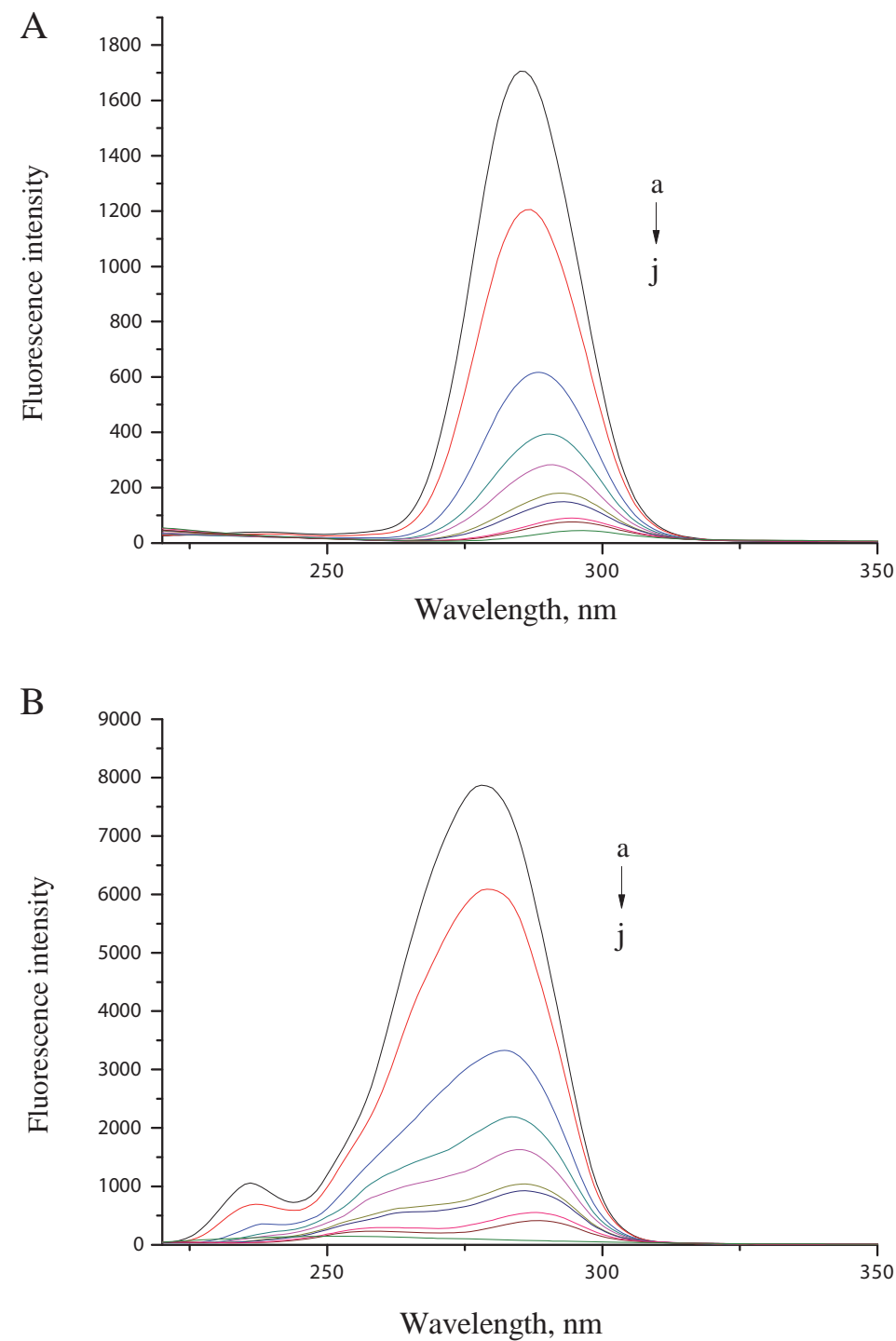

Fig. 4. Synchronous fluorescence spectra of interaction between pepsin with EGCG at $\Delta \lambda=15 \mathrm{~nm}$ (A) and $\Delta \lambda=60$ $\mathrm{nm}$ (B). (a-j) Pepsin was $1.0 \times 10^{-6} \mathrm{M}$, and EGCG concentration increased from 0.0, 2.0, 4.0, 6.0, 8.0, 10.0, 12.0, $14.0,16.0,18.0\left(\times 10^{-6} \mathrm{M}\right)$ at $37^{\circ} \mathrm{C}$.

The FTIR spectra of pepsin and the EGCG-pepsin complex with their different absorption spectrum are shown in Figure 5A and B, respectively. The protein amide I (1600$\left.1700 \mathrm{~cm}^{-1}\right)$ and amide II $\left(\approx 1540 \mathrm{~cm}^{-1}\right)$ are both related to the protein secondary structure (TANTIPOLPHAn et al., 2007). The peak position of the amide II band moved from 1541 to 1533 $\mathrm{cm}^{-1}$, so the addition of EGCG caused the secondary structure change of pepsin. 

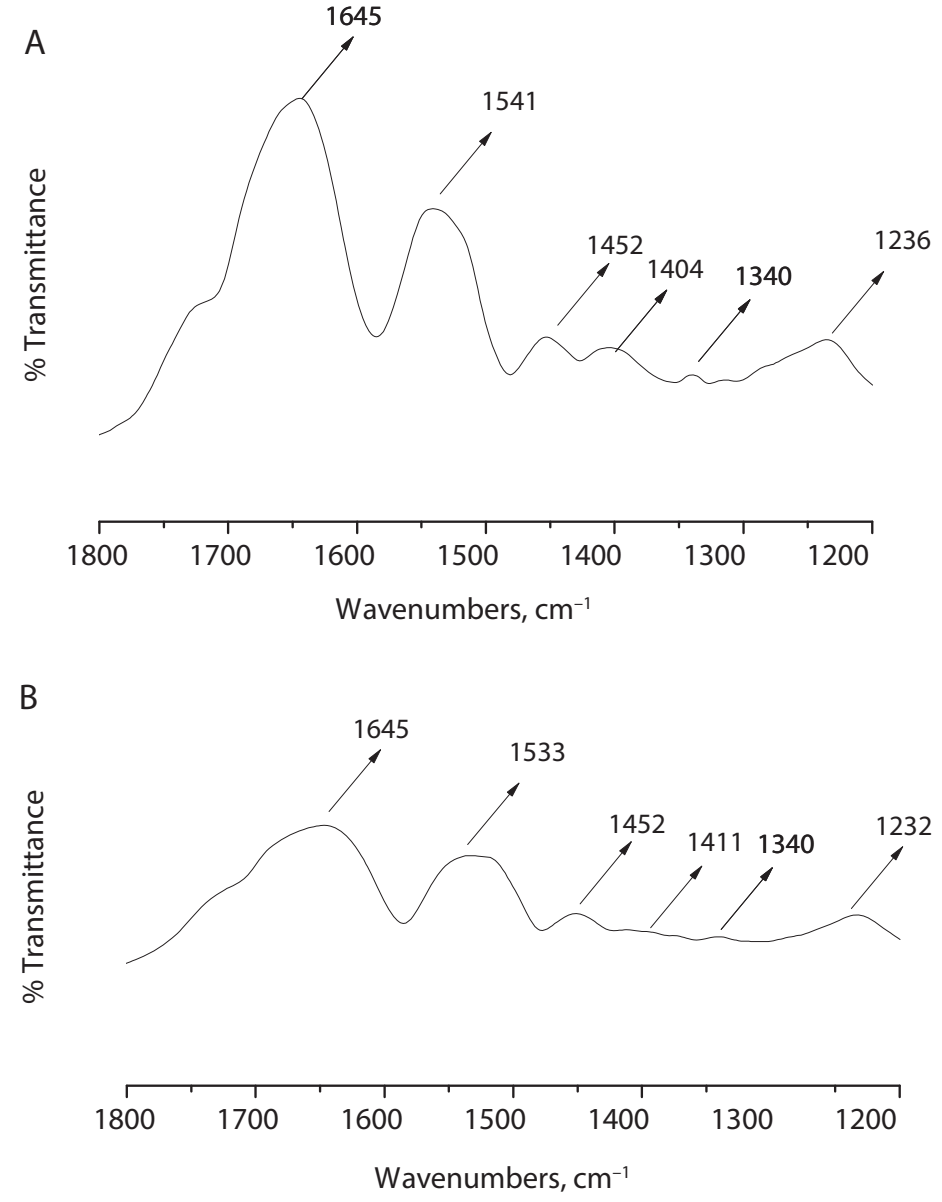

Fig. 5. FTIR spectra of pepsin (A) and pepsin-EGCG complex (B) in the region of $1200-1800 \mathrm{~cm}^{-1}$.

The quantitative analyses of the protein secondary structure for free pepsin and in complex with EGCG are in Table 1. The free pepsin contained $16.0 \% \alpha$-helix, $35.2 \% \beta$-sheet, and $34.4 \%$ turn. Upon EGCG interaction, the $\beta$-sheet proportion decreased and the $\alpha$-helix proportion increased slightly. Thus, pepsin bound by EGCG changed its native conformation.

Table 1. Secondary structures for analysis (infrared spectra) of free pepsin and in complex with (-)-epigallocatechin-3-gallate (EGCG).

\begin{tabular}{lccc}
\hline $\begin{array}{l}\text { Secondary structural } \\
\text { elements }\end{array}$ & $\begin{array}{c}\text { Peak position } \\
\left(\mathrm{cm}^{-1}\right)\end{array}$ & $\begin{array}{c}\text { Pepsin } \\
(\%)\end{array}$ & Pepsin-EGCG $(\%)$ \\
\hline$\alpha$-Helix & 1645 & 16.0 & 17.1 \\
$\beta$-Sheet & $1615-1635$ & 35.2 & 30.2 \\
Turn & $1665-1693$ & 34.4 & 37.4 \\
Random & 1655 & 14.4 & 15.3 \\
\hline
\end{tabular}




\subsection{Molecular modelling and docking}

Our results from the multi-spectroscopy method were substantiated by docking with EGCG molecules docked to pepsin to determine the preferred binding sites (Fig. 6). EGCG was surrounded by Pro-29, Leu-155, Ala-22, Arg-154, Asp-153, Trp-141, His-40, Ser-32, Glu-70, and IIe-80. Hydrogen bonding interaction appeared plausible between Glu-70, Asp-153, and Ser-32.
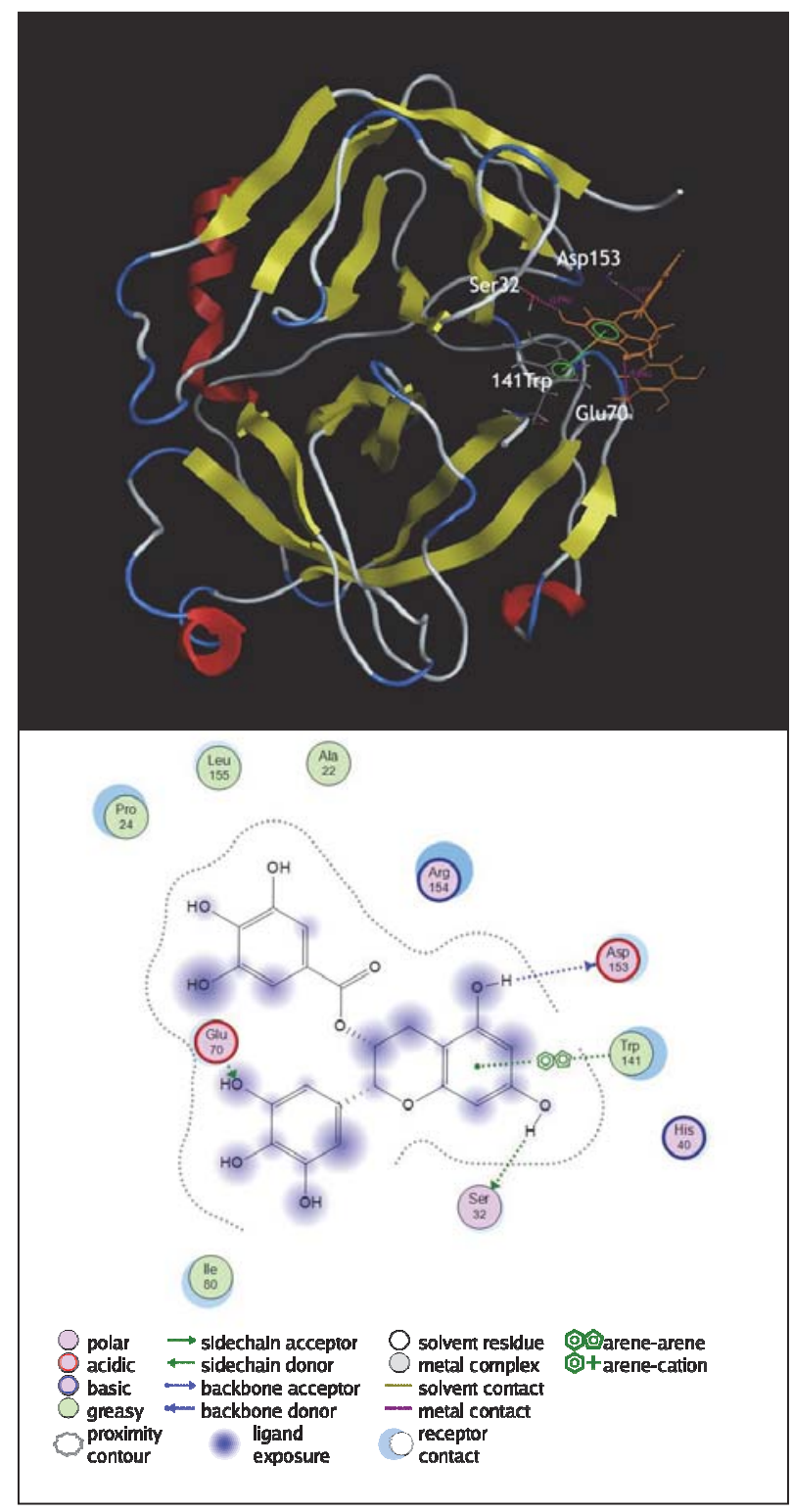

Fig. 6. Best docked conformations of EGCG-pepsin complex. Pepsin residues of interest and EGCG represented as sticks. Amino acid residues thought to interact with EGCG are shown as a 2D representation by using LigX in MOE. 
Non-covalent interaction is considered the main interaction between tea polyphenols and proteins (Siebert et al., 1996; YAn et al., 2009; Wu et al., 2011, 2012, 2014). EGCG contains galloyl and hydroxyl groups. The galloyl groups exhibit certain hydrophobicity and the phenolic groups can form hydrogen bonds with the protein polar groups $(\mathrm{NH} 2, \mathrm{OH}$, and SH group) (HE et al., 2006; XIAO et al, 2007). In this study, we found that electrostatic force accompanied by hydrophobic binding might play important roles in the increased binding affinity of EGCG with pepsin. These non-covalent -bond interactions between EGCG and pepsin may alter the polarity of the fluorophore environment. The alteration may have been achieved by the hydrophobic interactions of phenolic compounds with the interior hydrophobic groups of the protein and by the subsequent formation of hydrogen bonds between the $\mathrm{OH}$ groups of phenolic compounds with polar groups of the protein. Our docking studies further supported our experimental observations of the binding interactions. Furthermore, EGCG inhibiting pepsin activity might be non-competitive, without binding the catalytic sites of pepsin. The activity of pepsin may be changed because of its specific conformation changes.

\section{Conclusions}

In summary, results of our studies suggest that EGCG could bind pepsin with a change in the native conformation of pepsin. Green tea is rich source of various polyphenols. The antioxidant properties of polyphenols make them beneficial to health. On the other hand, polyphenols can interact with enzymatic proteins subsequently changing their molecular configuration, which leads to reducing the catalytic activity of digestive enzymes (BANDYOPADHYAY et al., 2012). Thus, understanding of interaction between polyphenols and digestive enzymes, it is important to minimize the antinutritional effects of polyphenols. Our findings provide an important insight into the interaction between the physiologically important protein pepsin and the most potent constituent of green tea, EGCG, which further contributes to an understanding of the binding interaction between green tea catechins and digestive enzymes.

This study was supported in part by the Research Funding of Guangdong Province (nos 2015A030313558, 2015A010107017 and WSTJJ20140101440508197710190438) and Research Funding of Shenzhen (nos. JCYJ20140418091413497 and CXZZ20150529165110750) to Xuli Wu.

\section{References}

Bandyopadhyay, P., Ghosh, A.K. \& Ghosh, C. (2012): Recent developments on polyphenol-protein interactions: effects on tea and coffee taste, antioxidant properties and the digestive system. Food Funct., 3, 592-605.

Byler, D.M. \& Susi, H. (1986): Examination of the secondary structure of proteins by deconvolved FTIR spectra. Biopolymers, 25, 469-487.

Dong, A., Huang, P. \& Caughey, W.S. (1990): Protein secondary structures in water from second-derivative amide I infrared spectra. Biochemistry, 29, 3303-3308.

Dubeau, S., Samson, G. \& TajmiR-Riahi, H.-A. (2010): Dual effect of milk on the antioxidant capacity of green, Darjeeling, and English breakfast teas. Food Chem., 122, 539-545.

He, Q., Lv, Y.P. \& YAo, K. (2006): Effects of tea polyphenols on the activities of $\alpha$-amylase, pepsin, trypsin and lipase. Food Chem., 101, 1178-1182. 
JiAng, C.Q., GaO, M.X. \& He, J.X. (2002): Study of the interaction between terazosin and serum albumin: Synchronous fluorescence determination of terazosin. Anal. Chim. Acta, 452, 185-189.

Kilmartin, P.A. \& Hsu, C.F. (2003): Characterisation of polyphenols in green, oolong, and black teas, and in coffee, using cyclic voltammetry. Food Chem., 82, 501-512.

Lakowicz, J R. (1999): Principles of fluorescence spectroscopy, $2^{\text {nd }}$ ed., Kluwer Academic/Plenum Publishers, New York, NY. 725 pages.

LAkowicz, J.R. \& Weber, G. (1973): Quenching of protein fluorescence by oxygen. Detection of structural fluctuations in proteins on the nanosecond time scale. Biochemistry, 12, 4171-4179.

Prigent, S.V., Gruppen, H., Visser, A.J., Van Koningsveld, G.A., De Jong, G.A. \& Voragen, A.G. (2003): Effect of non-covalent interactions with 5-O-coffeoylquinic acid (chlorogenic acid) on the heat denaturation and solubility of globular proteins. J. Agr. Food Chem., 51, 5088-5095.

Ross, P.D. \& Subramanian, S. (1981): Thermodynamics of protein association reactions: Forces contributing to stability. Biochemistry, 20, 3096-3102.

Sabu, M.C, Priya, T.T., Ramadasan, K. \& Ikuo, N. (2010): Beneficial effects of green tea: A literature review. Chinese Medicine, 5, 13-22.

Siebert, K.J., Troukhanova, N.V. \& Lynn, P.Y. (1996): Nature of polyphenol-protein interactions. J. Agr. Food Chem., 44, 80-85.

Sinkovits, A.F., Bryksa, B.C., TAnaka, T. \& YadA, R. Y. (2007): Understanding the structure-function role of specific catalytic residues in a model food related enzyme: pepsin. Enzyme Microb. Tech., 40, 1175-1180.

Spencer, C.M., Cai, Y., Martin, R., Gaffney, S.H., Goulding, P.N., Magnolato, D., Lilley, T.H., Haslam, E. (1988): Polyphenol complexation - some thoughts and observations. Phytochemistry, 27, 2397-2409.

Susi, H. \& Byler, D.M. (1986): Resolution-enhanced Fourier transform infrared spectroscopy of enzymes. Methods Enzymol., 130, 290-311.

Tantipolphan, R., Rades, T. \& Medlicott, N.J. (2007): Swelling lecithin: cholesterol implants for the controlled release of proteins. Int. J. Pharm., 337, 40-47.

WANG, C., Wu, Q.H., WANG, Z. \& ZhaO, J. (2006): Study of the interaction of carbamazepine with bovine serum albumin by fluorescence quenching method. Anal. Sci., 22, 435-438.

Wu, X.L., Wu, H., Liu, M.X., Liu, Z.H., Xu, H. \& Lai, F.R. (2011): Analysis of binding interaction between (-)-epigallocatechin (EGC) and $\beta$-lactoglobulin by multi-spectroscopic method. Spectrochim. Acta A., 82, $164-168$.

Wu, X.L., Raje, D., Wu, H., Liu, Z.G., He, Q.Q. \& Zeng, X.J. (2012): Studies on the interaction of EGCG with bovine $\beta$-lactoglobulin by spectroscopic methods and docking. Int. J. Dairy Technol., 65, 7-13.

Wu, X.L., He, W.Y., Li, Y., Zhang, H.P., Liu, Z.G., Wang, W.P., YE. Y. \& CAO, J.J. (2013): Characterization of binding interactions of (-)-epigallocatechin-3-gallate from green tea and lipase. J. Agr. Food Chem., 61, 8829-8835.

Wu, X.L., He, W.Y., Zhang, H.P., Li, Y., Liu, Z.G. \& He, Z.D. (2014): Acteoside: A lipase inhibitor from the Chinese tea Ligustrum purpurascens kudingcha. Food Chem., 142, 306-310.

Xiao, J.B., Shi, J., CaO, H., Wu, S.D., Ren, F.L. \& Xu, M. (2007): Analysis of binding interaction between puerarin and bovine serum albumin by multi-spectroscopic method. J. Pharmaceut. Biomed., 45, 609-615.

XIE, M.X., XU, X.Y. \& WANG, Y.D. (2005): Interaction between hesperetin and human serum albumin revealed by spectroscopic methods. BBA-Gen Subjects, 1724, 215-224.

YAN, Y., Hu, J. \& YAO, P. (2009): Effects of casein, ovalbumin, and dextran on the astringency of tea polyphenols determined by quartz crystal microbalance with dissipation. Langmuir, 25, 397-402.

Yuksel, Z., Avci, E. \& EReEM., Y.K. (2010): Characterization of binding interactions between green tea flavanoids and milk proteins. Food Chem., 121, 450-456.

ZHU, R.R., WANG, W.R., Sun, X.Y, LiU, H. \& WANG, S.L. (2010): Enzyme activity inhibition and secondary structure disruption of nano-TiO2 on pepsin. Toxicol. in Vitro., 24, 1639-1647. 